\title{
Peripherin Is a Subunit of Peripheral Nerve Neurofilaments: Implications for Differential Vulnerability of CNS and Peripheral Nervous System Axons
}

\author{
Aidong Yuan, ${ }^{1,2}$ Takahiro Sasaki, ${ }^{1}$ Asok Kumar, ${ }^{1,2}$ Corrinne M. Peterhoff, ${ }^{1}$ Mala V. Rao, ${ }^{1,2}$ Ronald K. Liem, ${ }^{4}$ \\ Jean-Pierre Julien, ${ }^{5}$ and Ralph A. Nixon ${ }^{1,2,3}$ \\ ${ }^{1}$ Center for Dementia Research, Nathan Kline Institute, Orangeburg, New York 10962, Departments of ${ }^{2}$ Psychiatry and ${ }^{3}$ Cell Biology, New York University \\ School of Medicine, New York, New York 10016, ${ }^{4}$ Department of Pathology, College of Physicians and Surgeons, Columbia University, New York, New York \\ 10032, and ${ }^{5}$ Centre de Recherche du Centre Hospitalier de l'Université Laval, Département d'Anatomie et Physiologie de l'Université Laval, Québec G1V \\ 4G2, Canada
}

Peripherin, a neuronal intermediate filament protein implicated in neurodegenerative disease, coexists with the neurofilament triplet proteins [neurofilament light (NFL), medium (NFM), and heavy (NFH) chain] but has an unknown function. The earlier peak expression of peripherin than the triplet during brain development and its ability to form homopolymers, unlike the triplet, which are obligate heteropolymers, have supported a widely held view that peripherin and neurofilament triplets form separate filament systems. However, here, we demonstrate that, despite a postnatal decline in expression, peripherin is as abundant as the triplet in the adult PNS and exists in a relatively fixed stoichiometry with these subunits. Peripherin exhibits a distribution pattern identical to those of triplet proteins in sciatic axons and colocalizes with NFL on single neurofilaments by immunogold electron microscopy. Peripherin also coassembles into a single network of filaments containing NFL, NFM, and NFH with and without $\alpha$-internexin in quadruple- or quintuple-transfected SW13vim (-) cells. Genetically deleting NFL in mice dramatically reduces peripherin content in sciatic axons. Moreover, peripherin mutations has been shown to disrupt the neurofilament network in transfected SW13vim(-) cells. These data show that peripherin and the neurofilament proteins are functionally interdependent. The results strongly support the view that, rather than forming an independent structure, peripherin is a subunit of neurofilaments in the adult PNS. Our findings provide a basis for its close relationship with neurofilaments in PNS diseases associated with neurofilament accumulation.

\section{Introduction}

Neurofilaments (NFs) in the mature CNS are composed of four subunits, NF heavy chain (NFH), NF medium chain (NFM), NF light chain (NFL), and $\alpha$-internexin (Yuan et al., 2006). In most adult peripheral nerves, however, $\alpha$-internexin is markedly downregulated during embryonic development to hardly detectable levels, and its disappearance from the PNS coincides with the appearance of another intermediate filament (IF) protein, peripherin (Escurat et al., 1990). After its discovery as a $57 \mathrm{kDa}$ Triton X-100-insoluble protein (Portier et al., 1982, 1983a,b;

\footnotetext{
Received March 5, 2012; revised April 24, 2012; accepted May 3, 2012.

Author contributions: A.Y. designed research; A.Y., T.S., A.K., and C.M.P. performed research; A.Y., M.V.R., R.K.L., J.-P.J., and R.A.N. analyzed data; A.Y. and R.A.N. wrote the paper.

This work was supported by National Institutes on Aging Grant AG05604 (R.A.N). We thank Nicole Piorkowski for manuscript preparation, Arthur Saltzman for histological assistance, Veeranna for purified NFL, and Timo Meerloo (University of California, San Diego, La Jolla, (A) for his help with postembedding immunoelectron microscopy.

The authors declare no competing financial interests.

Correspondence should be addressed to Dr. Aidong Yuan or Dr. Ralph A. Nixon, Center for Dementia Research, Nathan Kline Institute, New York University School of Medicine, 140 Old Orangeburg Road, Orangeburg, NY 10962. E-mail: yuan@nki.rfmh.org or nixon@nki.rfmh.org.

T. Sasaki's present address: Department of Peripheral Nervous System, National Institute of Neuroscience, National Center of Neurology and Psychiatry, 4-1-1 Ogawa-higashi, Kodaira, Tokyo 187-8502, Japan.

DOI:10.1523/JNEUROSCI.1081-12.2012

Copyright $\odot 2012$ the authors $\quad 0270-6474 / 12 / 328501-08 \$ 15.00 / 0$
}

Tatemoto et al., 1982), peripherin was established as a type III IF protein based on its structural properties and ability to assemble into filaments by itself or together with either NF proteins or vimentin (Portier et al., 1983a; Parysek and Goldman, 1987; Leonard et al., 1988; Thompson and Ziff, 1989; Cui et al., 1995; Ho et al., 1995; Athlan and Mushynski, 1997). Although its neuronal specificity and abundance in axons led early investigators to suspect that peripherin, like $\alpha$-internexin, may be a subunit of NFs (Portier et al., 1983a), little evidence has been brought to bear on this possibility (Barry et al., 2007; Mclean and Robertson, 2011). Moreover, other studies have supported the view that peripherin forms a separate filament system (Ferri et al., 1990; Troy et al., 1990; Wong and Oblinger, 1990; Beaulieu et al., 1999), although the evidence is indirect. For example, peripherin can form homopolymers (Cui et al., 1995; Ho et al., 1995), unlike NF triplets that are obligate heteropolymers (Ching and Liem, 1993; Lee et al., 1993). Also, peripherin gene expression is highest in late embryonic and early postnatal brain and declines somewhat before expression of triplet protein sharply rises (Kost et al., 1992). Peripherin and NF gene expression is also regulated differentially in nerve regeneration (Troy et al., 1990; Wong and Oblinger, 1990; Belecky-Adams et al., 1993). These studies have lead to a prevailing view that the NFs in the mature PNS are composed of 

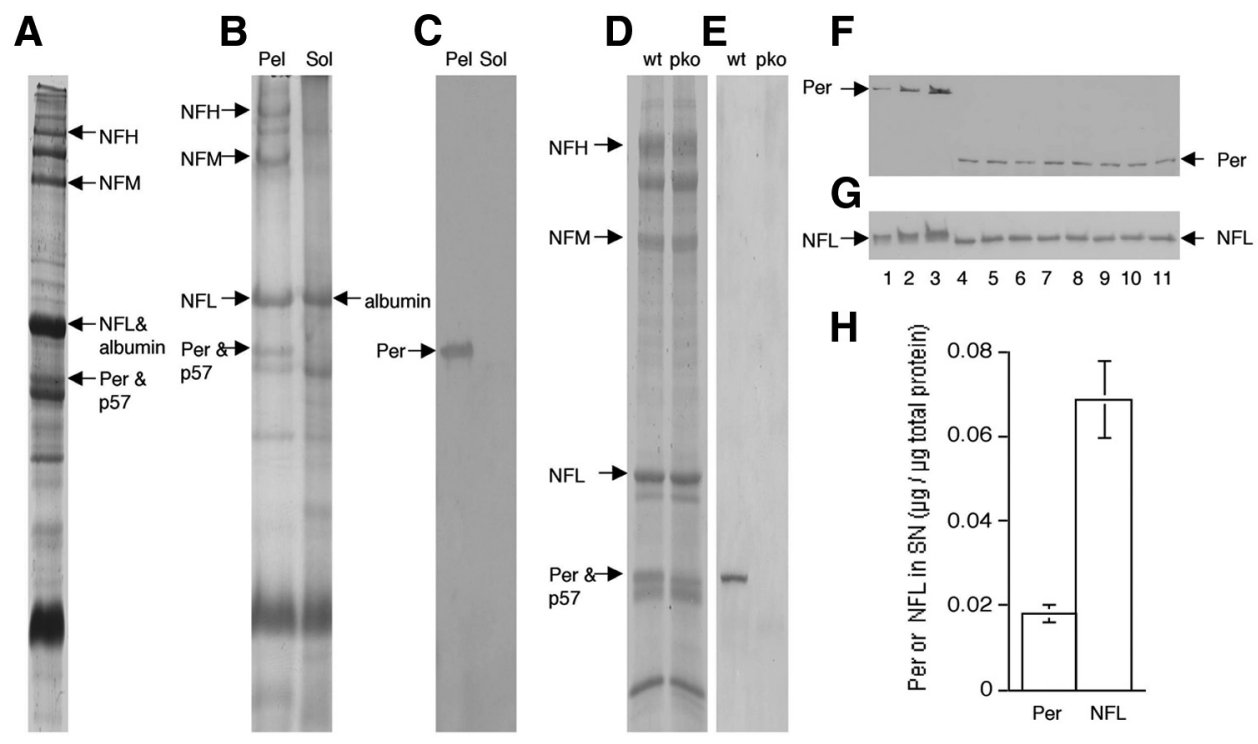

Figure 1. Peripherin is as abundant as the NF triplet in the adult PNS and exists in a relatively fixed stoichiometry with these subunits. Peripherin was identified as one of the major proteins in the sciatic nerve of 3-month-old mice by Coomassie blue staining $(\boldsymbol{A})$ and is Triton X-100 insoluble ( $\boldsymbol{B})$. The peripherin protein was recognized by anti-peripherin antibody on immunoblot $(\boldsymbol{C})$. The $57 \mathrm{kDa}$ peripherin band stained by Coomassie blue is contaminated by another Triton X-100-insoluble protein ( $p 57$ ) as evidenced by its presence in peripherin knock-out mice (D), and peripherin deletion was confirmed by immunoblotting with specific anti-peripherin antibody $(\boldsymbol{E})$. Measurement of peripherin and NFL in sciatic nerve homogenates by quantitative immunoblotting $(\boldsymbol{F}, \boldsymbol{G})$. Purified peripherin with a $26 \mathrm{kDa}$ GST tag or purified NFL was used as standard in separate immunoblots and incubated with either anti-peripherin or anti-NFL. F, Lanes 1,2, 3, Purified peripherin at 40,80, and $160 \mathrm{ng}$, respectively. G, Lanes 1, 2, 3, Purified NFL at 9, 18, and $36 \mathrm{ng}$, respectively. Lanes $4-11$, Homogenates from eight different sciatic nerves of eight mice. Peripherin is as abundant as the $\mathrm{NF}$ triplet in the adult PNS and exists in a relatively fixed stoichiometry with these subunits. The molar ratio is estimated to be 3.5:1 (NFL/peripherin) based on quantitative immunoblotting $(\boldsymbol{H})$. NF triplets were identified by immunoblotting with specific antibodies and also by their disappearance in Triton X-100-insoluble fractions from corresponding knock-out mice (NFH knock-out, NFM knock-out, and NFL knock-out). Note that the 68 kDa Triton X-100-soluble protein (B), which contaminates NFL in homogenates $(\boldsymbol{A})$, was previously identified as serum albumin (Soifer et al., 1981). Per, Peripherin; Pel, pellet; Sol, soluble; wt, wild-type; pko, peripherin knock-out.

three subunits (Elder et al., 1998; Yuan et al., 2006), although the physiological roles of peripherin, in fact, remain incompletely understood.

Beyond its important neurobiological implications, understanding the function of peripherin and its relationship to NFs takes on additional significance in light of the recent identification of peripherin mutations in amyotrophic lateral sclerosis (ALS) (Gros-Louis et al., 2004; Leung et al., 2004; Corrado et al., 2011), a neurodegenerative disorder in which a pathological hallmark is the abnormal accumulation of NFs in motor neurons (Hirano et al., 1984; Kondo et al., 1986; Munoz et al., 1988; Mizusawa et al., 1989; Strong et al., 2001).

To investigate the possibility that peripherin serves a role in the mature PNS analogous to $\alpha$-internexin in CNS, we studied the behavior and distribution of peripherin under physiological conditions in vivo and in other conditions in which NF behaviors were altered by genetically deleting specific NF subunits. Our data identify important new structural and functional relationships between peripherin and NF triplets. Moreover, by applying criteria used previously to establish the triplets as NF subunits and $\alpha$-internexin in CNS (Yuan et al., 2006), we obtained strong evidence that peripherin is a fourth subunit of NFs in the mature PNS. Our studies reconcile previous observations on peripherin, including the similar behavior of peripherin and the NF triplet proteins in pathological states, and they reveal a potential basis for the differential vulnerability of CNS and PNS neurons in neurological diseases.

\section{Materials and Methods}

Generation of knock-out animals. Adult male or female mice of the C57BL/6J strain, 3-12 months old at the time they were killed, were used in all experiments. Mice were housed at $23^{\circ} \mathrm{C}$ on a $12 \mathrm{~h} \mathrm{light/dark} \mathrm{cycle}$ and were maintained on Lab Chow (Purina Mills) supplied ad libitum.
Productions of NFL knock-out (LKO) and peripherin knock-out have been described previously (Zhu et al., 1997; Larivière et al., 2002). All experimental protocols were approved by the New York University and Nathan Kline Institute Institutional Animal Care and Use Committees under the guidelines of the Institutional Animal Care and Use Committee of the United States.

SDS-PAGE and immunoblot analysis. Protein concentrations were determined with bicinchoninic acid (BCA) assay (Sigma-Aldrich). SDSPAGE was performed according to Laemmli (1970). Separated proteins were transferred to nitrocellulose membranes (Millipore). Blots were probed with primary antibodies, followed by an alkaline phosphataseconjugated secondary antibody (12,500-fold dilution; Dako). The reaction was developed using a BCIP/NBT phosphatase system (KPL) as described previously (Yuan et al., 1997). Sciatic nerves from LKO and wild-type controls were homogenized in $500 \mu \mathrm{l}$ of buffer (SDS buffer) containing $25 \mathrm{~mm}$ sodium phosphate, pH 7.2, 5 mm EGTA, 1\% SDS, and $1 \mathrm{~mm}$ phenylmethylsulfonyl fluoride (PMSF), and protein concentration was measured with the BCA assay (Sigma-Aldrich). Loading onto gels was normalized to total protein of the nerves. Alternatively, a specific length of sciatic nerve segment $(6 \mathrm{~mm})$ from each mouse was homogenized in $125 \mu \mathrm{l}$ of buffer containing $25 \mathrm{~mm}$ sodium phosphate, $\mathrm{pH}$ 7.2, 5 mM EGTA, 1\% SDS, and $1 \mathrm{~mm}$ PMSF. Three microliters of the nerve extract were loaded into individual lanes of SDS-PAGE gels. Blots were probed with peripherin antibodies against total peripherin. For the experiment to estimate the relative amount of NF proteins in the mature nervous system, optic pathways ( $\sim 1.5 \mathrm{mg}$ wet weight) or similar amount of corpus callosum were homogenized in $250 \mu \mathrm{l}$ of SDS buffer, whereas sciatic nerves $(\sim 4.5 \mathrm{mg}$ wet weight $)$ or similar amounts of spinal cord were homogenized in $500 \mu \mathrm{l}$ of SDS buffer and processed as above for immunoblotting with specific antibodies.

Estimation of peripherin content in sciatic nerve. Total protein extracts from $24 \mathrm{~mm}$ sciatic nerve were homogenized in $250 \mu \mathrm{l}$ of buffer containing 25 mm sodium phosphate, pH 7.2, 5 mm EGTA, 1\% SDS, and $1 \mathrm{~mm}$ phenylmethylsulfonyl fluoride, and protein concentration was measured with BCA assay (Sigma-Aldrich). One-dimensional 7.5, 10, or 12\% SDS- 


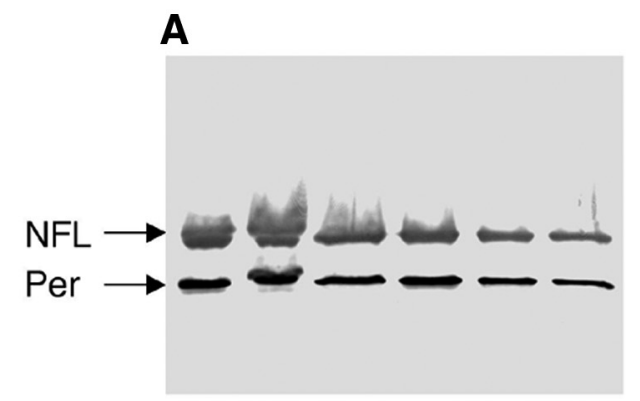

$\begin{array}{lllllll}\text { Segment \# } & 2 & 3 & 4 & 5 & 6 & 7\end{array}$

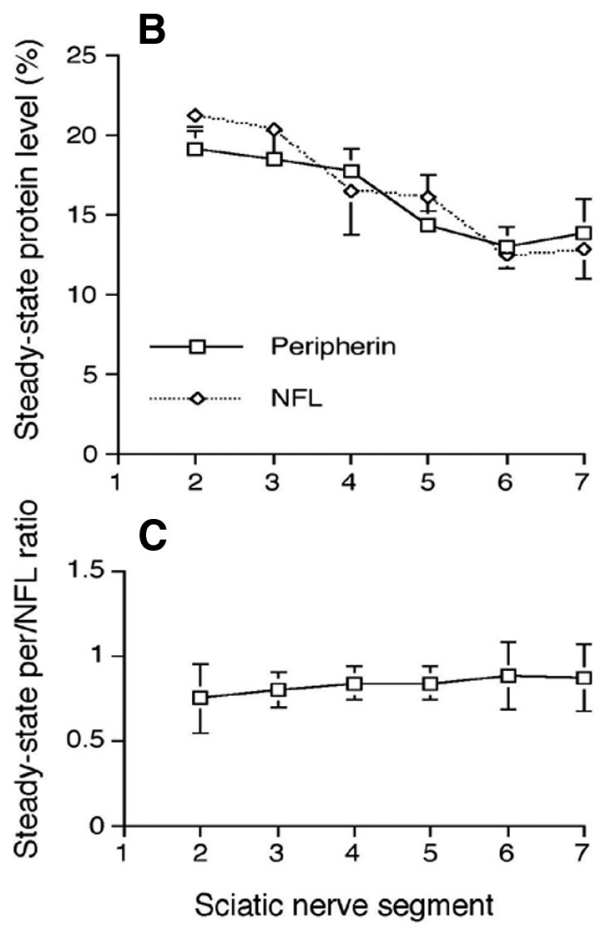

Figure 2. Distribution of peripherin and NFL along the sciatic nerve. Triton X-100-insoluble fractions from consecutive $3 \mathrm{~mm}$ segments of the sciatic nerve were separated by SDS-PAGE, transferred to nitrocellulose membranes, and then probed by anti-peripherin and anti-NFL antibodies $(\boldsymbol{A})$. Analyses of these immunoblots demonstrate that peripherin and NFL show the same proximal-to-distal distribution $(\boldsymbol{B})$ and maintain a constant ratio along the sciatic nerve (C). Per, Peripherin.

PAGE gels were used, and the PAGE-separated proteins were transferred to nitrocellulose membranes and immunoblotted using an alkalinephosphatase-conjugated indirect secondary antibody procedure. Major proteins were identified using appropriate antibodies. Purified recombinant peripherin (tagged with $26 \mathrm{kDa}$ GST) (Novus Biologicals) or purified NFL protein from mouse spinal cords (Rao et al., 2011) was used as a standard for protein estimation by quantitative immunoblotting. Sciatic nerves were also homogenized in $250 \mu \mathrm{l}$ of cytoskeleton extraction buffer (50 mm Tris-HCl, pH 6.8, 1\% Triton X-1000, 10\% glycerol, $0.15 \mathrm{M}$ $\mathrm{NaCl}, 2 \mathrm{~mm}$ EDTA, 2 mм PMSF, $50 \mu \mathrm{g} / \mathrm{ml}$ leupeptin, and $2.5 \mu \mathrm{g} / \mathrm{ml}$ aprotinin). The homogenate was centrifuged at $15,000 \times g$ for $30 \mathrm{~min}$ at $4^{\circ} \mathrm{C}$ to isolate Triton X-100-soluble and Triton X-100-insoluble particulate fractions. Gels were also stained with Coomassie Brilliant Blue R in $50 \%$ methanol $/ 10 \%$ acetic acid.

Antibodies used. Antibodies used were monoclonal antibodies to NFL (NR4), NFM (NN18), and NFH (N52) (Sigma) and $\alpha$-internexin (MAB5224; Millipore Bioscience Research Reagents). Antibodies also used were polyclonal antibodies (pAbs) to $\alpha$-internexin (AB5354; Millipore), NFL (AB9568; Millipore), NFM (prepared using purified mouse

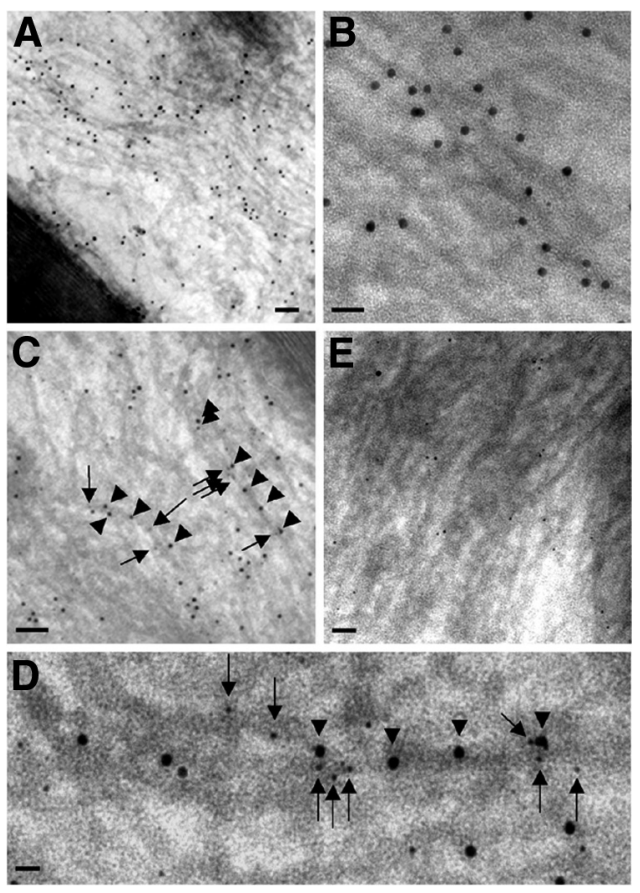

Figure 3. Ultrastructural colocalization of peripherin and NFL on the same NF in sciatic nerve by postembedding immunoelectron microscopy. Paraformaldehyde-fixed samples were incubated with rabbit anti-peripherin or mouse anti-NFL antibodies and probed with goat antirabbit lgG and goat anti-mouse lgG conjugated to 12 and $6 \mathrm{~nm}$ gold beads. As expected, for the immunodetection of peripherin in normal mice $(\boldsymbol{A})$, large numbers of $12 \mathrm{~nm}$ gold particles are aligned with most $10 \mathrm{~nm}$ filaments in the axon. $\boldsymbol{B}$, Higher magnification shows decoration of single filaments by $12 \mathrm{~nm}$ gold particles conjugated to anti-peripherin antibody. C, Linear arrays of two sizes of gold particles ( $12 \mathrm{~nm}$ for peripherin and $6 \mathrm{~nm}$ for NFL) decorate $10 \mathrm{~nm}$ filaments in the axon. $\boldsymbol{D}$, Higher magnification shows that gold particles of two sizes overlie a single filament in the background. Arrowheads point to $12 \mathrm{~nm}$ particles (peripherin) and arrows to 6 $\mathrm{nm}$ ones (NFL). $\boldsymbol{E}$, Negligible numbers of $12 \mathrm{~nm}$ gold particles (peripherin) are detected in peripherin knock-out mice, whereas $6 \mathrm{~nm}$ gold particles (NFL) are still present. Scale bars: $A, 150$ $\mathrm{nm} ; \boldsymbol{B}, 40 \mathrm{~nm} ; \boldsymbol{C}, 100 \mathrm{~nm} ; \boldsymbol{D}, 30 \mathrm{~nm} ; \boldsymbol{E}, 80 \mathrm{~nm}$.

NFM proteins as antigen), and NFH C-terminal 12 aa (Xu et al., 1993). Antibodies also used were mAbs to peripherin (MAB1527, MAB53807C5; Millipore Bioscience Research Reagents) (MAB8G2; Sigma) and $\mathrm{pAb}$ to peripherin (Millipore Bioscience Research Reagents).

Estimation of stoichiometry of peripherin and NFL along sciatic nerve. Consecutive $3 \mathrm{~mm}$ segments were cut from $24 \mathrm{~mm}$ sciatic nerves away from spinal cord and homogenized in $125 \mu \mathrm{l}$ of cytoskeleton extraction buffer (50 mu Tris-HCl, pH 6.8, 1\% Triton X-1000, 10\% glycerol, $0.15 \mathrm{~m}$ $\mathrm{NaCl}, 2 \mathrm{~mm}$ EDTA, $2 \mathrm{~mm}$ PMSF, $50 \mu \mathrm{g} / \mathrm{ml}$ leupeptin, and $2.5 \mu \mathrm{g} / \mathrm{ml}$ aprotinin). The homogenate was centrifuged at $15,000 \times g$ for $30 \mathrm{~min}$ at $4^{\circ} \mathrm{C}$ to isolate Triton X-100-soluble and Triton X-100-insoluble particulate fractions. The pellets were then dissolved in sample preparation buffer ( $1 \%$ SDS, $10 \%$ glycerol, $10 \% \beta$-mercaptoethanol, and $250 \mathrm{~mm}$ Tris, pH 6.8) and heated for $10 \mathrm{~min}$. Equal volumes were loaded onto each lane, and the PAGE-separated proteins were transferred to nitrocellulose membranes and immunoblotted with anti-peripherin or anti-NFL antibodies. The molar stoichiometries between peripherin and NFL along the sciatic nerve were estimated by computer densitometry using NIH Image as described previously (Yuan et al., 2006).

Immunoelectron microscopy. Peripherin null and wild-type mice, anesthetized with isoflurane, were perfused intracardially with $4 \%$ paraformaldehyde in $0.1 \mathrm{~m}$ phosphate buffer, $\mathrm{pH} 7.4$, followed by fixation of the removed sciatic nerves for $4 \mathrm{~h}$ in fresh fixative on ice. Ultrathin cryosections were prepared as described previously for postembedding immunostaining (Zheng et al., 2004). Peripherin was detected using rabbit pAb (Millipore Bioscience Research Reagents), followed by a 12-nm goldconjugated goat anti-rabbit antibody. NFL was detected using a mouse $\mathrm{mAb}$ (NR4; Sigma), followed by 6-nm gold-conjugated goat anti-mouse. 

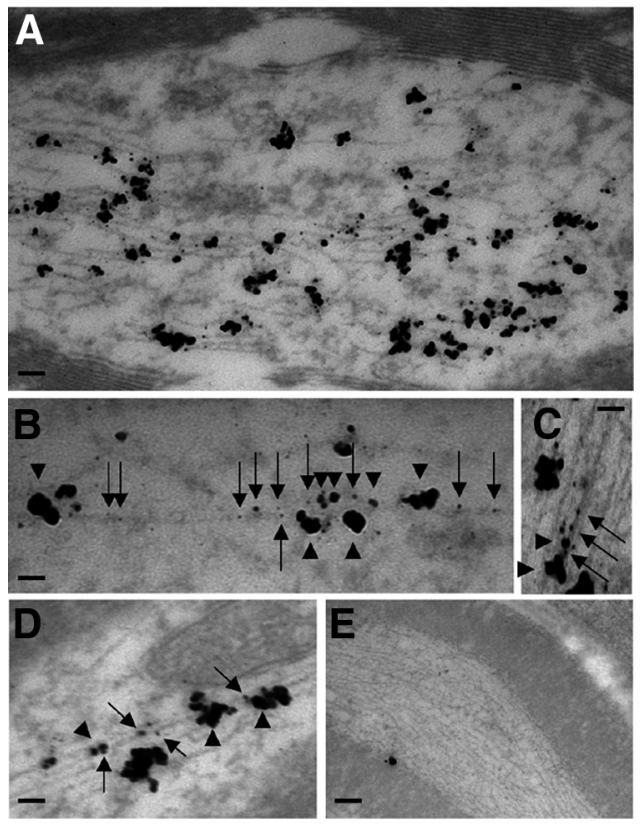

Figure 4. Ultrastructural colocalization of peripherin and NFL on the same NF in sciatic nerve by preembedding immunoelectron microscopy. Paraformaldehyde-fixed samples were incubated with rabbit anti-peripherin and mouse anti-NFL antibodies and probed with goat antirabbit lgG and goat anti-mouse lgG conjugated to $0.6 \mathrm{~nm}$ gold beads. Single (for anti-mouse $\operatorname{lgG}$ ) or double (for anti-rabbit lgG) silver enhancement of gold particles resulted in irregularshaped electron-dense particles that could be distinguished by their size. As expected, for the immunodetection of peripherin and NFL in normal mice $(A)$, linear arrays of two sizes of gold particles (large for peripherin and small for NFL) decorate most $10 \mathrm{~nm}$ filaments in the axon, and negligible numbers are detected in peripherin knock-out mice $(\boldsymbol{E})$. Higher magnification shows that gold particles of two sizes overlie a single filament in the background $(\boldsymbol{B}-\boldsymbol{D})$. Arrows point to small particles (NFL) and arrowheads to large ones (peripherin). Scale bars: $\boldsymbol{A}, 100 \mathrm{~nm} ; \boldsymbol{B}, 60$ $\mathrm{nm} ; \boldsymbol{C}, 40 \mathrm{~nm} ; \boldsymbol{D}, 50 \mathrm{~nm} ; \boldsymbol{E}, 200 \mathrm{~nm}$.

Sections were observed and photographed on a Jeol 1200 EXII transmission electron microscope. For alternative preembedding immunoelectron microscopy, $50 \mu \mathrm{m}$ vibratome sections were incubated with polyclonal anti-peripherin or monoclonal anti-NFL and processed for double immunogold-silver labeling as described previously (Verkade et al., 1997; Yi et al., 2001). Differentiation of the double labeling was achieved by incubating with one ultrasmall gold conjugate (0.6-nm goldconjugated goat anti-rabbit antibody), followed by silver enhancement and then incubating with the second ultrasmall gold conjugate $(0.6-\mathrm{nm}$ gold-conjugated goat anti-mouse antibody), followed by additional silver enhancement. This resulted in two groups of silver-enhanced particles: smaller particles enhanced once and larger particles enhanced twice. After fixing, postfixing in osmium, and routine processing for electron microscopy, ultrathin sections are stained with alcoholic uranyl acetate before imaging. The grids were photographed on a Jeol $100 \mathrm{cx}$ electron microscope operated at $80 \mathrm{kV}$.

Immunofluorescence of SW13vim(-) cells. SW13vim(-) cells were cultured in DMEM with $10 \%$ fetal bovine serum, $100 \mathrm{U} / \mathrm{ml}$ penicillin, and 0.1 $\mathrm{mg} / \mathrm{ml}$ streptomycin. Transfection into SW13(-) cells was performed using Lipofectamine 2000 (Invitrogen) according to the instructions of the manufacturer. Immunofluorescence staining of SW13vim(-) cells were performed as described previously (Sasaki et al., 2006; Yuan et al., 2009). The expression plasmid of mouse NFL, NFM, and NFH were constructed by cloning into pcDNA3.1. The expression plasmid of rat $\alpha$-internexin (pRSVi- $\alpha$ ) and rat peripherin (pRSVi-per) were used as described previously (Ching and Liem, 1993; Ho et al., 1995). NFL was probed with rabbit pAb NA1214 (500-fold dilution; Affiniti Research Products). NFM was probed with mouse mAb NN18 (500-fold dilution; SigmaAldrich) or anti-NFM rabbit pAb (200-fold dilution) prepared using purified mouse NFM proteins as antigen. NFH was probed with mouse mAb N52 (2000-fold dilution) or anti-NFH rabbit pAb raised against the
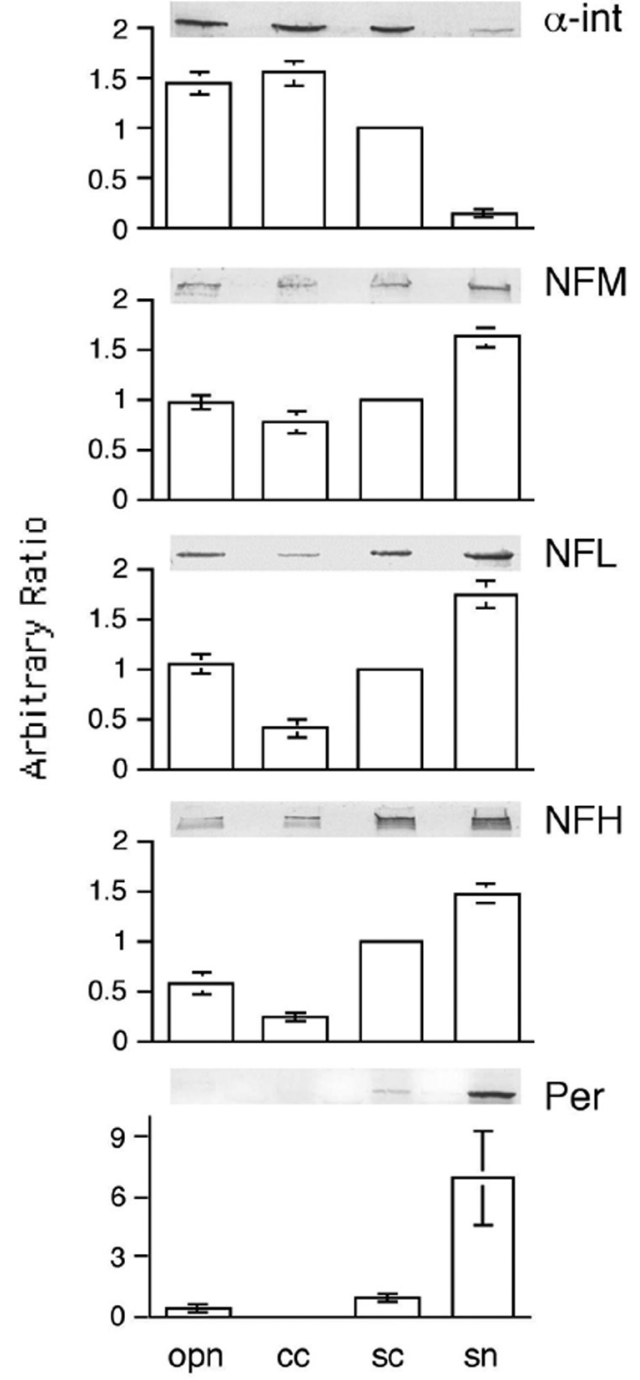

Figure 5. The distribution of peripherin is complementary to that of $\alpha$-internexin in the mature nervous system. The relative amount of peripherin, $\alpha$-internexin, NFL, NFM, and NFH in the mature nervous system (represented by optic pathway, corpus callosum, spinal cord, and sciatic nerve) was estimated by SDS-PAGE and immunoblotting (examples shown). Data are presented from multiple experiments (mean $\pm \mathrm{SEM}, n=4$ ) as column graphs normalized to spinal cord. Note that the distribution of peripherin is complementary to that of $\alpha$-internexin. opn, Optic pathway; cc, corpus callosum; sc, spinal cord; sn, sciatic nerve; $\alpha$-int, $\alpha$-internexin; Per, peripherin.

COOH-terminal 12 aa of mouse NFH (2000-fold dilution) (Xu et al., 1993 ), and rat $\alpha$-internexin was probed with anti- $\alpha$-internexin mouse mAb MAB5224 (200-fold dilution). Rat peripherin was probed with anti-peripherin mouse mAb MAB5380 (100-fold dilution) (clone 7C5; Millipore). Images were observed under an LSM 510 laser scanning confocal microscope (Carl Zeiss).

\section{Results}

\section{Stable stoichiometry of peripherin and NFL in sciatic} axonal NFs

In mouse sciatic axons, peripherin was identified on SDS gels as a $57 \mathrm{kDa}$ protein that is exclusively Triton X-100 insoluble (Fig. $1 A, B)$ and recognized by anti-peripherin antibody on immunoblots (Fig. 1C). Because the $57 \mathrm{kDa}$ peripherin band is contaminated by another Triton X-100-insoluble protein (here we name it p57) (Fig. $1 D, E$ ), we choose not to use Coomassie blue staining to estimate peripherin content in sciatic nerves. Quantitative im- 


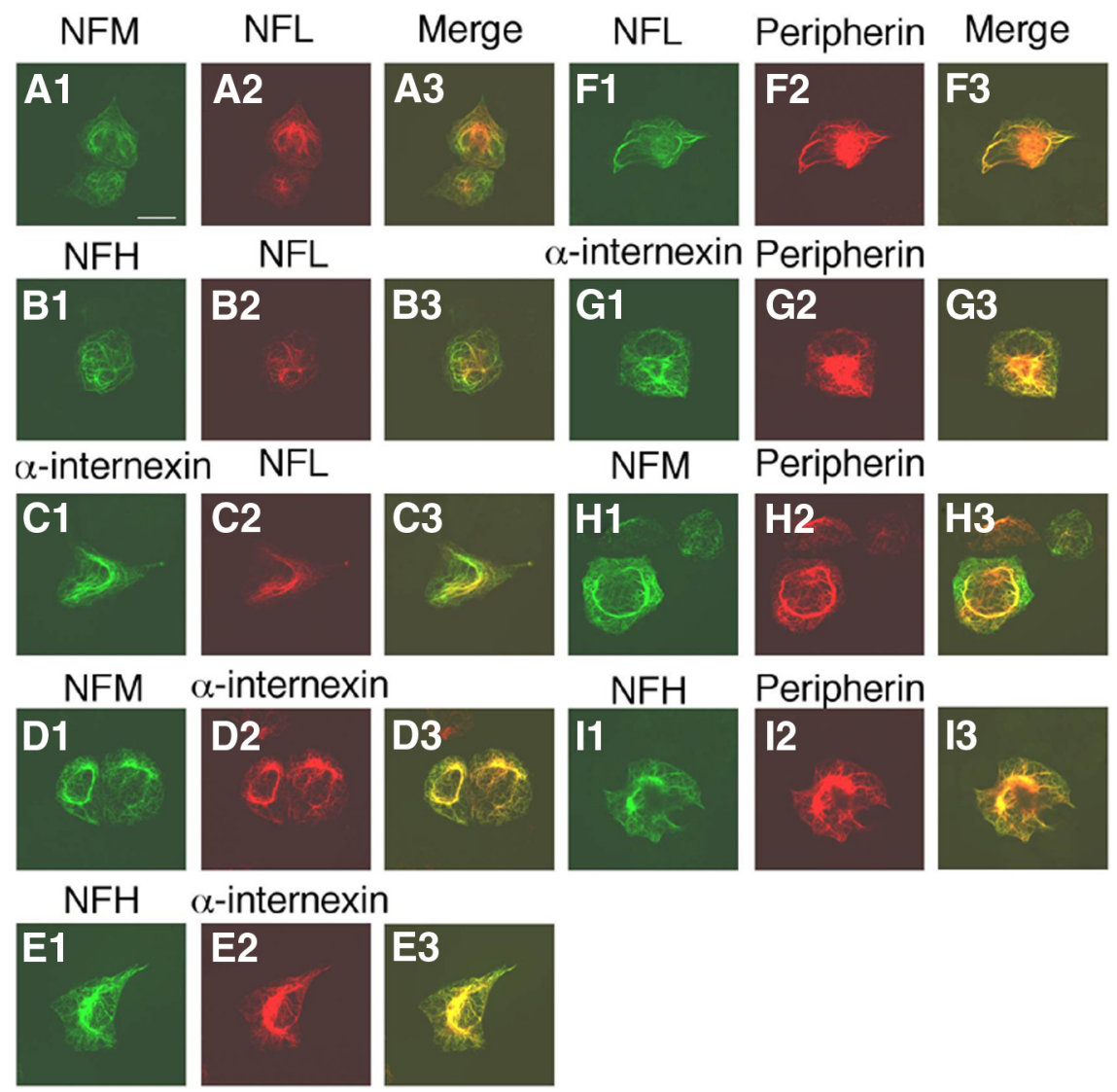

Figure 6. Coassembly of peripherin with NF triplets and $\alpha$-internexin into single filament network. SW13vim(-) cells were quintuple-transfected with constructs that expressed peripherin, NFL, NFM, NFH, and $\alpha$-internexin and were immunostained with pairs of antibodies. Each set of three panels across represents the single immunolabels and the merged double label (yellow indicating colocalization) for the following pairs of antibodies: $A$ 1-A3, rabbit pAbs to NFL and mouse $m A b s$ to NFM; $B$ 1-B3, rabbit pAb to NFL and mouse mAb to NFH; C1-C3, rabbit pAb to NFL and mouse mAb to $\alpha$-internexin; D1-D3, rabbit pAb to NFM and mouse $\mathrm{mAb}$ to $\alpha$-internexin; $\boldsymbol{E} \mathbf{1}-\boldsymbol{E} \mathbf{3}$, rabbit pAb to NFH and mouse mAb to $\alpha$-internexin; $\boldsymbol{F 1}-\boldsymbol{F}$, rabbit pAb to NFL and mouse mAb to peripherin; G1-G3, rabbit pAb to $\alpha$-internexin and mouse mAb to peripherin; $\boldsymbol{H 1}-\boldsymbol{H} \mathbf{3}$, rabbit pAb to NFM and mouse $\mathrm{mAb}$ to peripherin; I1-I3, rabbit pAb to NFH and mouse mAb to peripherin. Scale bar, $20 \mu \mathrm{m}$.

munoblotting with purified peripherin and NFL revealed that peripherin constituted $1.83 \pm 0.21 \%$ (mean $\pm \mathrm{SD}, n=8$ ) of total protein in sciatic nerve (Fig. $1 F, H$ ), whereas NFL constituted $\sim 6.88 \pm 0.90 \%$ (mean \pm SD, $n=8$ ) (Fig. $1 G, H)$. NFs decrease in number proximally to distally along sciatic axons (Schlaepfer and Bruce, 1990). Additional immunoblots demonstrated that peripherin and NFL display the same degree of proximal-to-distal decline in content, maintaining a constant ratio along the sciatic axons (Fig. 2; mean $\pm \mathrm{SD}, n=3$ ).

\section{Ultrastructural colocalization of peripherin and NFL on} single NF in sciatic axons

To determine whether peripherin and NFL coexist on the same NF in mouse sciatic axons, we performed ultrastructural colocalization studies of these two proteins using pAb antiperipherin and $\mathrm{mAb}$ anti-NFL and double immunogold labeling. Thin sections of paraformaldehyde-fixed sciatic nerve were incubated with rabbit anti-peripherin $\mathrm{pAb}$ and mouse anti-NFL mAb (NR4) and then stained with goat anti-rabbit and anti-mouse IgG conjugated with 12 and $6 \mathrm{~nm}$ gold particles, respectively. When rabbit anti-peripherin and mouse anti-NFL antibodies were incubated with the sections, the respective immunogold-conjugated secondary antibodies detected both peripherin and NFL associated with the same $10 \mathrm{~nm}$ filaments (Fig.
$3 C, D)$, and the specificity of this interaction was confirmed by the negligible labeling of peripherin in peripherin knock-out animals (Fig. 3E). Colocalization of peripherin and NFL on single NF in sciatic nerve was also demonstrated by double immunogold-silver labeling procedure (Fig. 4A-D), and the specificity of this interaction was also confirmed by the negligible labeling of peripherin in peripherin knock-out animals (Fig. 4E).

Quantitative immunoblot measurements (ratios) of peripherin, $\alpha$-internexin, NFL, NFM, and NFH in the corpus callosum, optic nerve, spinal cord, and sciatic nerve of mature mice using phosphorylation-independent antibodies highlighted the considerable regional heterogeneity of subunit stoichiometry. Peripherin exhibited a stoichiometric relationship complementary to that of $\alpha$-internexin in NFs with high levels of peripherin in sciatic nerve and low but not absent levels in CNS regions (Fig. 5). In contrast, $\alpha$-internexin was comparably abundant in corpus callosum, optic nerve, and spinal cord but was barely detectable in sciatic nerve, consistent with growing evidence that NFM is the key subunit regulating NF transport. NFM levels in optic nerve, spinal cord, and sciatic nerve were comparable in CNS and PNS regions. Similarly, NFL was comparably distributed across PNS and CNS tissue but less abundant in corpus callosum, in which NF numbers and axon calibers are the lowest among these regions. Conversely, NFH proportions were most variable across regions and correlated generally with the average calibers and abundance of NFs in the four fiber tracts (Fig. 5).

Peripherin coassembles with other NF subunit proteins into a single filament network

Previous studies have shown that all peripherin can coassemble with NFL or NFL plus NFH in double- or triple-transfected SW13vim (-) cells to form the same NF network (Beaulieu et al., 1999). However, it is not known whether peripherin selfassembles into its own separate filamentous network, when all five proteins (peripherin, $\alpha$-internexin, NFH, NFM, and NFL) are present in the same cell as in the immature PNS (Chiu et al., 1989) or can form complete NFs. SW13vim(-) cells lacking cytoplasmic IFs were, therefore, quintuple transfected with constructs that expressed peripherin, $\alpha$-internexin, NFH, NFM, and NFL and were immunostained with mouse mAbs to peripherin, $\alpha$-internexin, or NFL and rabbit pAbs to $\alpha$-internexin, NFL, NFM, and NFH. Double-immunofluorescence analyses with pairs of these antibodies confirmed that all five proteins coassembled into a single network of filaments (Fig. 6). Under conditions in which all four proteins (peripherin, NFH, NFM, and NFL) coexist in the same cell, such as in the mature PNS, we also observed that all peripherin coassembles with all three NF proteins into a single filamentous network rather than forming its own separate filamentous network. In immunofluorescence studies similar to those above, SW13vim(-) cells expressing pe- 

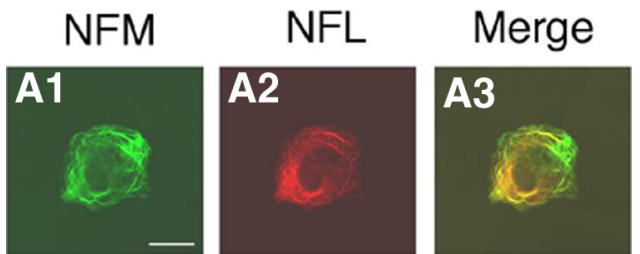

$\mathrm{NFH}$

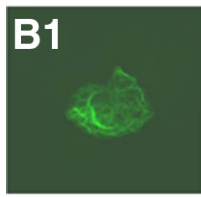

NFL
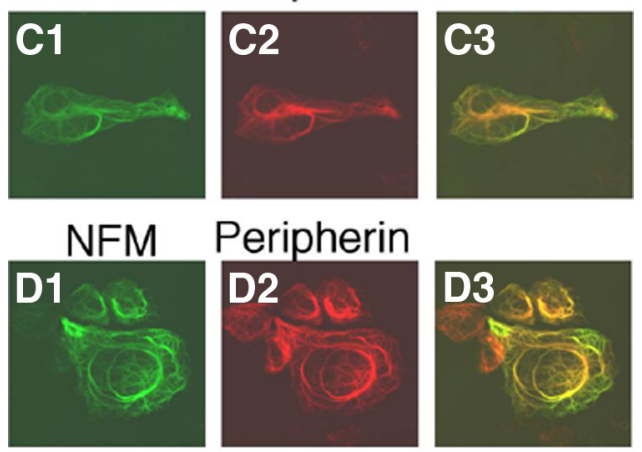

Peripherin
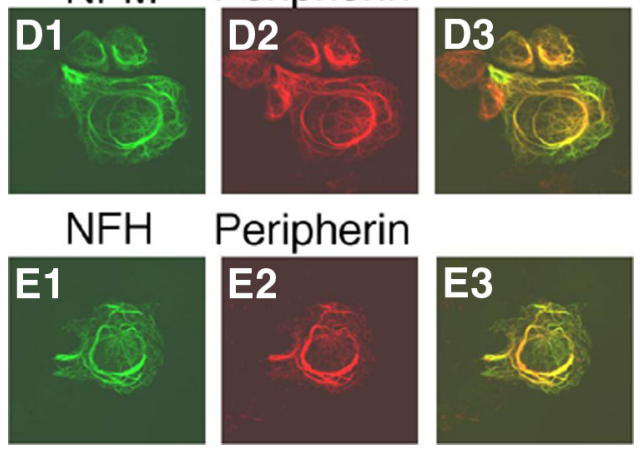

Figure 7. Coassembly of peripherin with NF triplet proteins into single filament network. SW13vim (-) cells were quadruple transfected with constructs that expressed peripherin, NFL, NFM, and NFH and were immunostained with pairs of antibodies. Each set of three panels across represents the single immunolabels and the merged double label (yellow indicating colocalization) for the following pairs of antibodies: $\mathbf{A 1 - A 3}$, rabbit pAbs to NFL and mouse mAbs to NFM; B1-B3, rabbit pAb to NFL and mouse mAb to NFH; C1-C3, rabbit pAb to NFL and mouse mAb to peripherin; D1-D3, rabbit $\mathrm{pAb}$ to NFM and mouse $\mathrm{mAb}$ to peripherin; $\boldsymbol{E}$ 1-E3, rabbit $\mathrm{pAb}$ to $\mathrm{NFH}$ and mouse mAb to peripherin. Scale bar, $20 \mu \mathrm{m}$.

ripherin, NFH, NFM, and NFL coassembled into a single network of filaments (Fig. 7).

\section{Dependence of peripherin on NFL in vivo}

We next examined quantitatively how deleting NFL influences the levels of peripherin. The steady-state level of peripherin in sciatic nerves of 3-month-old mice was decreased to $28.08 \pm$ $9.38 \%$ of wild-type level in the absence of NFL (mean \pm SD, $n=4)$, whereas those of NFM and NFH were decreased to $4.70 \pm 1.95 \%($ mean $\pm \mathrm{SD}, n=4)$ and $14.00 \pm 3.00 \% \%$ (mean $\pm \mathrm{SD}, n=4$ ), respectively (Fig. $8 A, B$ ). The level of vimentin was not significantly altered in NFL-deleted sciatic nerves (data not shown). Electron microscopy studies confirmed the scarcity of NFs in sciatic axons from 3-month-old LKO mice (Fig. $8 C, C 1, D, D 1)$, indicating that peripherin cannot self-assemble efficiently into filaments without NFL in vivo and NF subunits accumulated in cell bodies (Williamson et al., 1998). Peripherin also accumulated slightly in some of the motor and sensory cell bodies in NFL-deleted mice (Fig. 9).
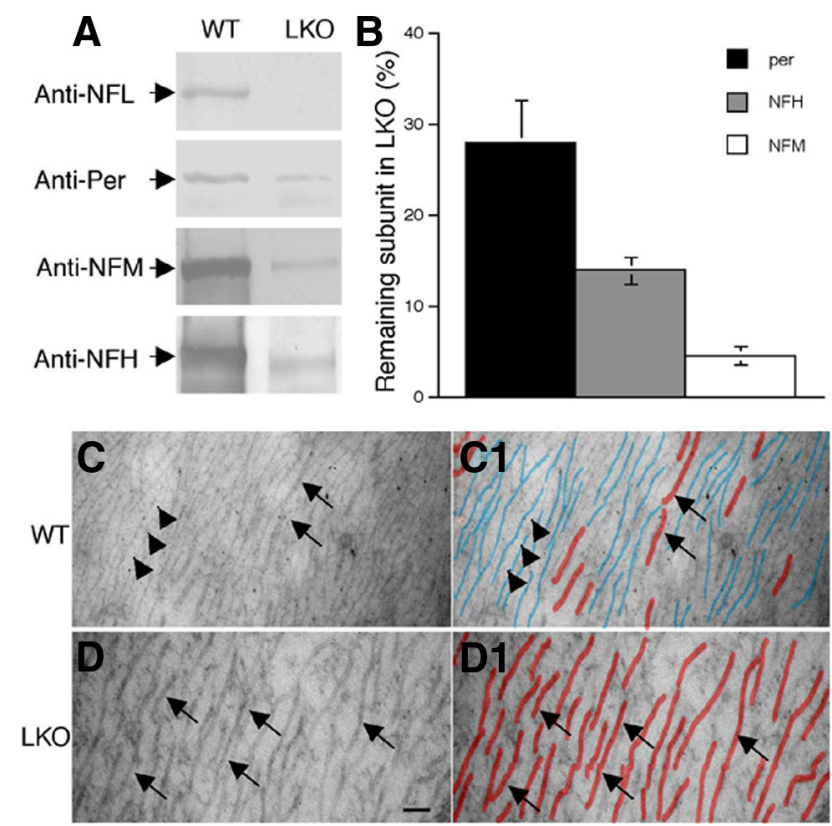

Figure 8. Dependence of peripherin on NF subunit NFL. Protein extracts prepared from sciatic nerves of wild-type and LKO mice were separated on SDS polyacrylamide gel and transferred to nitrocellulose membrane. Membranes were probed with anti-NFL, anti-peripherin, anti-NFM, and anti-NFH antibodies $(\boldsymbol{A})$. Note that peripherin, NFH, and NFM was reduced to $28.1,14$, and $4.7 \%$ in the absence of NFL compared with those in wild-type mice $(\boldsymbol{B})$. Rarity of NFs was confirmed by electron microscopy in the sciatic axons of LKO mice compared with wild-type controls whose NFs outnumber microtubules by as much as 10:1 (C, D). NFs and microtubules are traced by blue and red colors, respectively $(\mathbf{C} 1, \mathbf{D 1})$. Arrows point to microtubules, and arrowheads point to NFs. Scale bar, $100 \mathrm{~nm}$. Per, Peripherin.

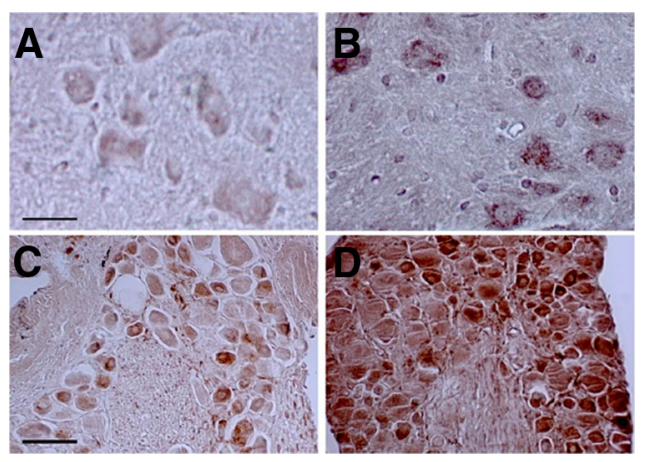

Figure 9. Higher levels of peripherin immunoreactivity in motor and sensory cell bodies in mice deleted for NFL. Peripherin was detected with anti-peripherin antibody in motor or sensory cell bodies in paraffin-embedded spinal cord $(\boldsymbol{A}, \boldsymbol{B})$ or dorsal root ganglion sections $(\boldsymbol{C}, \boldsymbol{D})$ from normal mice $(\boldsymbol{A}, \boldsymbol{C})$ or mice deleted for NFL $(\boldsymbol{B}, \boldsymbol{D})$. Scale bars: $\boldsymbol{A}, \boldsymbol{B}, 10 \mu \mathrm{m} ; \boldsymbol{C}, \boldsymbol{D}, 20 \mu \mathrm{m}$.

\section{Discussion}

In this study, we demonstrate, by all criteria used previously to establish the NF "triplet proteins" as subunits of NFs, that peripherin is a fourth subunit of PNS NFs. Although peripherin is a neuronal IF protein based on its coassembly in vitro with NF proteins (Beaulieu et al., 1999), this property does not establish it as an NF subunit. Nestin and vimentin are also neuronal IF proteins but are not NF subunits. Moreover, NF proteins coassemble in vitro with other IF proteins, such as vimentin and keratin, which are clearly not NF subunits (Monteiro and Cleveland, 1989; Carter et al., 1997). Our results, coupled with previous findings on $\alpha$-internexin, establish that NFs in mature CNS and PNS neurons are four subunit polymers. 
Peripherin copurified with NF triplets from Triton X-100insoluble fractions in amounts comparable with those of the other subunits and exhibited a stable stoichiometry with NFL along mature PNS axons in which NF number declines distally. We also demonstrated in quintuple-transfected SW13vim(-) cells, for the first time, that peripherin coassembles into a single filamentous network with all four NF proteins, as seen in immature PNS (Chiu et al., 1989), or with NF triplets, as seen in the mature PNS. Moreover, peripherin colocalizes with NFL on the same NF and in a molar ratio of 3.5:1 (NFL/peripherin) in isolated NFs from adult sciatic nerve. Based on molar ratios of NF subunits isolated from bovine spinal cord are 4:2:1 (NFL/NFM/ NFH) (Scott et al., 1985), we calculate that the molar ratio of the quadruplets in isolated NFs from sciatic nerve is $\sim 4: 2: 1: 1$ (NFL/ $\mathrm{NFM} /$ peripherin/NFH). A functionally meaningful association of peripherin with the NF triplet in vivo was strongly supported by evidence that peripherin levels and filaments are dramatically reduced in adult sciatic nerves in the absence of NFL. Our findings are consistent with reports that peripherin coassembles with NFL in SW13vim( - ) cells (Beaulieu et al., 1999) and that peripherin mutations disrupt the NF network in SW13vim $(-)$ cells (Parysek et al., 1991; Leung et al., 2004). Peripherin and NF proteins are transported at the same rate (Chadan et al., 1994) and are present in the same filament (Parysek et al., 1991; Yan et al., 2007). Moreover, overexpressing an NFH-LacZ fusion protein in mice induces peripherin to aggregate with the NF triplet in neuronal perikarya (Eyer and Peterson, 1994).

In the absence of NFL in sciatic nerve, only $4.7 \%$ of NFM were detected. This is in sharp contrast to the optic nerve in which $50 \%$ of the NFM still remains after NFL is deleted (Yuan et al., 2003). This difference is likely attributable to the presence of abundant $\alpha$-internexin in optic axons because additional deletion of $\alpha$-internexin in the absence of NFL and NFH abolishes NFM transport and NFM is undetectable (data not shown). These results highlight the much greater ability of the type IV IFs $\alpha$-internexin and NFM to partner together than peripherin, a type III IF protein, as previous findings suggest (Ching and Liem, 1993; Beaulieu et al., 1999). Although deletions of both NFH and NFM significantly affect $\alpha$-internexin, deletions of both NFH and NFL in optic axons have little effect on $\alpha$-internexin because $50 \%$ NFM is still present and can partner with the $\alpha$-internexin (Yuan et al., 2003). Similarly, in the PNS, the remaining peripherin could partner with remaining NFM and NFH to form oligomeric structures, as in SW13vim(-) cells (Beaulieu et al., 1999).

Peripherin pathology has been increasingly reported in neurodegenerative diseases associated with NF accumulation or mislocation. Our evidence that peripherin is a NF subunit in adult PNS provides a basis for this close association. Peripherin mutations in the rod domain (D141Y or R133P) cause ALS (Leung et al., 2004; Corrado et al., 2011), possibly through disruption of NF networks (Parysek et al., 1991; Leung et al., 2004). In one ALS case, a pathogenic peripherin gene mutation was associated with distinctive large perikaryal aggregates containing peripherin and NF triplet (Leung et al., 2004). A frame-shift deletion in the peripherin gene has also been shown to disrupt NF assembly in a subgroup of cases of ALS (Gros-Louis et al., 2004). Peripherin and NF protein also coexist in spinal spheroids of ALS (Corbo and Hays, 1992). Peripherin overexpression (fourfold to sevenfold) in transgenic mice slows NF transport (Millecamps et al., 2006) and promotes late-onset death of motor neurons (Beaulieu et al., 1999). The axonal transport of peripherin and NF triplet proteins is similarly impaired by $\beta$ - $\beta^{\prime}$-iminodipropionitrile (Griffin et al., 1978) or aluminum (Bizzi et al., 1984).
Interestingly, mutations of peripherin, NFL, and NFH, subunits most abundant in the PNS, are associated primarily with peripheral nerve disorders, such as Charcot-Marie-Tooth disease and ALS (Braissant, 2007; Yum et al., 2009), whereas dysfunction of $\alpha$-internexin is associated primarily with CNS disorders, such as NF inclusion disease, a form of frontal temporal dementia (Cairns et al., 2004). Mutations of NFM, a subunit abundant in both PNS and CNS axons, are associated with both PNS and CNS disorders, such as ALS and Parkinson's disease (Braissant, 2007). Thus, the associations of particular NF subunits with PNS or CNS disease match the relative abundance of the subunit in the mature CNS or PNS. Our results suggest that differences in NF subunit composition between the CNS and PNS should be considered as a possible contributing factor to the differential vulnerability of these neural systems in pathological states.

\section{References}

Athlan ES, Mushynski WE (1997) Heterodimeric associations between neuronal intermediate filament proteins. J Biol Chem 272:31073-31078.

Barry DM, Millecamps S, Julien JP, Garcia ML (2007) New movements in neurofilament transport, turnover and disease. Exp Cell Res 313: $2110-2120$.

Beaulieu JM, Robertson J, Julien JP (1999) Interactions between peripherin and neurofilaments in cultured cells: disruption of peripherin assembly by the NF-M and NF-H subunits. Biochem Cell Biol 77:41-45.

Belecky-Adams T, Wight DC, Kopchick JJ, Parysek LM (1993) Intragenic sequences are required for cell type-specific and injury-induced expression of the rat peripherin gene. J Neurosci 13:5056-5065.

Bizzi A, Crane RC, Autilio-Gambetti L, Gambetti P (1984) Aluminum effect on slow axonal transport: a novel impairment of neurofilament transport. J Neurosci 4:722-731.

Braissant O (2007) Neurofilament proteins in brain diseases. In: New research on neurofilament proteins (Arlen AK, ed), pp 25-51. New York: Nova Science Publishers.

Cairns NJ, Zhukareva V, Uryu K, Zhang B, Bigio E, Mackenzie IR, Gearing M, Duyckaerts C, Yokoo H, Nakazato Y, Jaros E, Perry RH, Lee VM, Trojanowski JQ (2004) alpha-Internexin is present in the pathological inclusions of neuronal intermediate filament inclusion disease. Am J Pathol 164:2153-2161.

Carter JE, Robertson J, Anderton BH, Gallo JM (1997) Incorporation of NF-L into keratin filaments in transfected epithelial cells. Neuroreport 8:2225-2228.

Chadan S, Le Gall JY, Di Giamberardino L, Filliatreau G (1994) Axonal transport of type III intermediate filament protein peripherin in intact and regenerating motor axons of the rat sciatic nerve. J Neurosci Res 39:127-139.

Ching GY, Liem RK (1993) Assembly of type IV neuronal intermediate filaments in nonneuronal cells in the absence of preexisting cytoplasmic intermediate filaments. J Cell Biol 122:1323-1335.

Chiu FC, Barnes EA, Das K, Haley J, Socolow P, Macaluso FP, Fant J (1989) Characterization of a novel $66 \mathrm{kd}$ subunit of mammalian neurofilaments. Neuron 2:1435-1445

Corbo M, Hays AP (1992) Peripherin and neurofilament protein coexist in spinal spheroids of motor neuron disease. J Neuropathol Exp Neurol 51:531-537.

Corrado L, Carlomagno Y, Falasco L, Mellone S, Godi M, Cova E, Cereda C, Testa L, Mazzini L, D’Alfonso S (2011) A novel peripherin gene (PRPH) mutation identified in one sporadic amyotrophic lateral sclerosis patient. Neurobiol Aging 32:552.e1-6.

Cui C, Stambrook PJ, Parysek LM (1995) Peripherin assembles into homopolymers in SW13 cells. J Cell Sci 108:3279-3284.

Elder GA, Friedrich VL Jr, Bosco P, Kang C, Gourov A, Tu PH, Lee VM, Lazzarini RA (1998) Absence of the mid-sized neurofilament subunit decreases axonal calibers, levels of light neurofilament (NF-L), and neurofilament content. J Cell Biol 141:727-739.

Escurat M, Djabali K, Gumpel M, Gros F, Portier MM (1990) Differential expression of two neuronal intermediate-filament proteins, peripherin and the low-molecular-mass neurofilament protein (NF-L), during the development of the rat. J Neurosci 10:764-784.

Eyer J, Peterson A (1994) Neurofilament-deficient axons and perikaryal ag- 
gregates in viable transgenic mice expressing a neurofilament-betagalactosidase fusion protein. Neuron 12:389-405.

Ferri GL, Sabani A, Abelli L, Polak JM, Dahl D, Portier MM (1990) Neuronal intermediate filaments in rat dorsal root ganglia: differential distribution of peripherin and neurofilament protein immunoreactivity and effect of capsaicin. Brain Res 515:331-335.

Griffin JW, Hoffman PN, Clark AW, Carroll PT, Price DL (1978) Slow axonal transport of neurofilament proteins: impairment of beta,beta'iminodipropionitrile administration. Science 202:633-635.

Gros-Louis F, Larivière R, Gowing G, Laurent S, Camu W, Bouchard JP, Meininger V, Rouleau GA, Julien JP (2004) A frameshift deletion in peripherin gene associated with amyotrophic lateral sclerosis. J Biol Chem 279:45951-45956.

Hirano A, Donnenfeld H, Sasaki S, Nakano I (1984) Fine structural observations of neurofilamentous changes in amyotrophic lateral sclerosis. J Neuropathol Exp Neurol 43:461-470.

Ho CL, Chin SS, Carnevale K, Liem RK (1995) Translation initiation and assembly of peripherin in cultured cells. Eur J Cell Biol 68:103-112.

Kondo A, Iwaki T, Tateishi J, Kirimoto K, Morimoto T, Oomura I (1986) Accumulation of neurofilaments in a sporadic case of amyotrophic lateral sclerosis. Jpn J Psychiatry Neurol 40:677-684.

Kost SA, Chacko K, Oblinger MM (1992) Developmental patterns of intermediate filament gene expression in the normal hamster brain. Brain Res 595:270-280.

Laemmli UK (1970) Cleavage of structural proteins during the assembly of the head of bacteriophage T4. Nature 227:680-685.

Larivière RC, Nguyen MD, Ribeiro-da-Silva A, Julien JP (2002) Reduced number of unmyelinated sensory axons in peripherin null mice. J Neurochem 81:525-532.

Lee MK, Xu Z, Wong PC, Cleveland DW (1993) Neurofilaments are obligate heteropolymers in vivo. J Cell Biol 122:1337-1350.

Leonard DG, Gorham JD, Cole P, Greene LA, Ziff EB (1988) A nerve growth factor-regulated messenger RNA encodes a new intermediate filament protein. J Cell Biol 106:181-193.

Leung CL, He CZ, Kaufmann P, Chin SS, Naini A, Liem RK, Mitsumoto H, Hays AP (2004) A pathogenic peripherin gene mutation in a patient with amyotrophic lateral sclerosis. Brain Pathol 14:290-296.

Mclean JR, Robertson J (2011) Peripherin pathology. In: Cytoskeleton of the nervous system (Yuan A, Nixon RA, eds), pp 201-224. New York: Springer.

Millecamps S, Robertson J, Lariviere R, Mallet J, Julien JP (2006) Defective axonal transport of neurofilament proteins in neurons overexpressing peripherin. J Neurochem 98:926-938.

Mizusawa H, Matsumoto S, Yen SH, Hirano A, Rojas-Corona RR, Donnenfeld H (1989) Focal accumulation of phosphorylated neurofilaments within anterior horn cell in familial amyotrophic lateral sclerosis. Acta Neuropathol 79:37-43.

Monteiro MJ, Cleveland DW (1989) Expression of NF-L and NF-M in fibroblasts reveals coassembly of neurofilament and vimentin subunits. J Cell Biol 108:579-593.

Munoz DG, Greene C, Perl DP, Selkoe DJ (1988) Accumulation of phosphorylated neurofilaments in anterior horn motoneurons of amyotrophic lateral sclerosis patients. J Neuropathol Exp Neurol 47:9-18.

Parysek LM, Goldman RD (1987) Characterization of intermediate filaments in PC12 cells. J Neurosci 7:781-791.

Parysek LM, McReynolds MA, Goldman RD, Ley CA (1991) Some neural intermediate filaments contain both peripherin and the neurofilament proteins. J Neurosci Res 30:80-91.

Portier MM, Croizat B, Gros F (1982) A sequence of changes in cytoskeletal components during neuroblastoma differentiation. FEBS Lett 146: 283-288.

Portier MM, de Néchaud B, Gros F (1983a) Peripherin, a new member of the intermediate filament protein family. Dev Neurosci 6:335-344.

Portier MM, Brachet P, Croizat B, Gros F (1983b) Regulation of peripherin in mouse neuroblastoma and rat PC 12 pheochromocytoma cell lines. Dev Neurosci 6:215-226.

Rao MV, Mohan PS, Kumar A, Yuan A, Montagna L, Campbell J, Veeranna, Espreafico EM, Julien JP, Nixon RA (2011) The myosin Va head domain binds to the neurofilament-L rod and modulates endoplasmic reticulum (ER) content and distribution within axons. PLoS One 6:e17087.

Sasaki T, Gotow T, Shiozaki M, Sakaue F, Saito T, Julien JP, Uchiyama Y,
Hisanaga S (2006) Aggregate formation and phosphorylation of neurofilament-L Pro22 Charcot-Marie-Tooth disease mutants. Hum Mol Genet 15:943-952.

Schlaepfer WW, Bruce J (1990) Neurofilament proteins are distributed in a diminishing proximodistal gradient along rat sciatic nerve. J Neurochem 55:453-460.

Scott D, Smith KE, O’Brien BJ, Angelides KJ (1985) Characterization of mammalian neurofilament triplet proteins. Subunit stoichiometry and morphology of native and reconstituted filaments. J Biol Chem 260:10736-10747.

Soifer D, Iqbal K, Czosnek H, De Martini J, Sturman JA, Wisniewski HM (1981) The loss of neuron-specific proteins during the course of Wallerian degeneration of optic and sciatic nerve. J Neurosci 1:461-470.

Strong MJ, Strong WL, Jaffe H, Traggert B, Sopper MM, Pant HC (2001) Phosphorylation state of the native high-molecular-weight neurofilament subunit protein from cervical spinal cord in sporadic amyotrophic lateral sclerosis. J Neurochem 76:1315-1325.

Tatemoto K, Carlquist M, Mutt V (1982) Neuropeptide Y: a novel brain peptide with structural similarities to peptide YY and pancreatic polypeptide. Nature 296:659-660.

Thompson MA, Ziff EB (1989) Structure of the gene encoding peripherin, an NGF-regulated neuronal-specific type III intermediate filament protein. Neuron 2:1043-1053.

Troy CM, Muma NA, Greene LA, Price DL, Shelanski ML (1990) Regulation of peripherin and neurofilament expression in regenerating rat motor neurons. Brain Res 529:232-238.

Verkade P, Schrama LH, Verkleij AJ, Gispen WH, Oestreicher AB (1997) Ultrastructural co-localization of calmodulin and B-50/growthassociated protein- 43 at the plasma membrane of proximal unmyelinated axon shafts studied in the model of the regenerating rat sciatic nerve. Neuroscience 79:1207-1218.

Williamson TL, Bruijn LI, Zhu Q, Anderson KL, Anderson SD, Julien JP, Cleveland DW (1998) Absence of neurofilaments reduces the selective vulnerability of motor neurons and slows disease caused by a familial amyotrophic lateral sclerosis-linked superoxide dismutase 1 mutant. Proc Natl Acad Sci USA 95:9631-9636.

Wong J, Oblinger MM (1990) Differential regulation of peripherin and neurofilament gene expression in regenerating rat DRG neurons. J Neurosci Res 27:332-341.

Xu Z, Cork LC, Griffin JW, Cleveland DW (1993) Increased expression of neurofilament subunit NF-L produces morphological alterations that resemble the pathology of human motor neuron disease. Cell 73:23-33.

Yan Y, Jensen K, Brown A (2007) The polypeptide composition of moving and stationary neurofilaments in cultured sympathetic neurons. Cell Motil Cytoskeleton 64:299-309.

Yi H, Leunissen J, Shi G, Gutekunst C, Hersch S (2001) A novel procedure for pre-embedding double immunogold-silver labeling at the ultrastructural level. J Histochem Cytochem 49:279-284.

Yuan A, Mills RG, Bamburg JR, Bray JJ (1997) Axonal transport and distribution of cyclophilin A in chicken neurones. Brain Res 771:203-212.

Yuan A, Rao MV, Kumar A, Julien JP, Nixon RA (2003) Neurofilament transport in vivo minimally requires hetero-oligomer formation. J Neurosci 23:9452-9458.

Yuan A, Rao MV, Sasaki T, Chen Y, Kumar A, Veeranna, Liem RK, Eyer J, Peterson AC, Julien JP, Nixon RA (2006) $\alpha$-Internexin is structurally and functionally associated with the neurofilament triplet proteins in the mature CNS. J Neurosci 26:10006-10019.

Yuan A, Sasaki T, Rao MV, Kumar A, Kanumuri V, Dunlop DS, Liem RK, Nixon RA (2009) Neurofilaments form a highly stable stationary cytoskeleton after reaching a critical level in axons. J Neurosci 29: $11316-11329$.

Yum SW, Zhang J, Mo K, Li J, Scherer SS (2009) A novel recessive Nefl mutation causes a severe, early-onset axonal neuropathy. Ann Neurol 66:759-770.

Zheng B, Lavoie C, Tang TD, Ma P, Meerloo T, Beas A, Farquhar MG (2004) Regulation of epidermal growth factor receptor degradation by heterotrimeric Galphas protein. Mol Biol Cell 15:5538-5550.

Zhu Q, Couillard-Després S, Julien JP (1997) Delayed maturation of regenerating myelinated axons in mice lacking neurofilaments. Exp Neurol 148:299-316 